\title{
CORRIGENDUM
}

\section{The effects of endothelial nitric oxide synthase tagSNPs on nitrite levels and risk of hypertension and obesity in children and adolescents}

JA de Miranda, R Lacchini, VA Belo, CMM Lanna, JT Sertorio, MR Luizon and JE Tanus-Santos

Journal of Human Hypertension (2015) 29, 140; doi:10.1038/jhh.2014.69

Correction to: Journal of Human Hypertension (2015) 29, 109-114; doi:10.1038/jhh.2014.48; published online 19 June 2014.

The author JT Sertorio was omitted from the author list. This has now been rectified and the corrected article appears in the issue.
The html and online PDF versions have also been corrected. The authors would like to apologise for their error. 